\title{
Anomalous Ossified Pterygospinous Ligament In Eastern Zone - A Case Study
}

\author{
Dr. Shweta Solan, Dr. Gokul Krishna Reddy Nune \\ Kallinga Institute Of Medical Sciences, Bhubaneswar, India.
}

\begin{abstract}
Ossification of pterygospinous ligament forms a bridge called as pterygospinous bony bridge, and when complete, may form pterygospinous foramen [Civinini's foramen]. The purpose of this study is to analyze the prevalence of ossification of these ligaments in eastern population of orissa and assess morphometrically the pterygospinous foramen. 50 dried skull were taken and studied for presence of pterygospinous foramen, but only one skull showed incomplete ossified pterygospinous ligament. Presence of this ligament can compress mandibular nerve, producing mandibular neuralgia and may interference in mandibular nerve block. This is important for radiologists, maxillofacial surgeons, dental surgeons and anaesthetists.

Keywords: Pterygospinous ligament, spine of sphenoid, lateral pterygoid plate, mandibular nerve.
\end{abstract}

\section{Introduction}

The pterygospinous ligament extends from lateral pterygoid plate to the spine of sphenoid bone. In standard textbooks of anatomy not much information about this ligament is given, except its extension from spine of sphenoid to the upper part of posterior border of lateral pterygoid plate. This ligament is ossifified sometimes, forming a foramen, which can be traversed by mandibular nerve branches to supply temporalis, masseter and lateral pterygoid muscle. ${ }^{1}$ Lingual nerve can be compressed between pterygoid muscle and pterygospinous bony bridge during contraction, producing numbness and pain during talking. ${ }^{2,3}$ The ossified pterygospinous ligament can interfere with mandibular nerve block used for pain relief in fractures of mandible or cancer patients ${ }^{4,5}$

\section{Materials and methods-}

The study was carried out at Kallinga institute of medical sciences[KIMS], Bhubaneswar, Orissa. 50 dried human skull were studied and presence of ossified pterygosphenoid ligament were noted. Undried and broken skulls were excluded from the study. Following criteria were noted-

1] ossified pterygospinous ligament.

2] formation of pterygospinous foramen- complete or incomplete.

3] distance between two ends of incomplete ossified pterygospinous ligament.

Dimensions were measured by verniers callipers upto nearest $\mathrm{mm}$.

\section{Observations-}

Out of 50 skulls studied, only one skull showed bilateral presence of ossified pterygospinous ligament. On left side, almost complete pterygospinous foramen was found[ fig.-1] and distance between two ends of ossified ligament was measured to be $2.3 \mathrm{~mm}$. On right side, incomplete ossification of pterygospinous ligament was found and distance between spine of sphenoid and posterior border of lateral pterygoid plate was measured to be $7.8 \mathrm{~mm}$ [ fig.-2].. In other skulls, no positive findings were observed.

\section{Discussion-}

The ligaments are fibrous bands which connect the adjacent bones, but when they ossify, they may lead to many clinical symptoms. ${ }^{6}$ The ossification of pterygospinous ligaments can produce difficulty in accessing the ovale foramen in a therapeutic approach. ${ }^{7}$ Compression of mandibular nerve and its branches may cause clinical conditions like lingual numbness, speech impairment, mandibular neuralgias,etc. ${ }^{8}$ A unusual course of lingual nerve with entrapment of the nerve between ossified pterygospinous ligament and medial pterygoid plate was found. ${ }^{2}$ Krmpotic et al. observed ossified pterygospinous ligament in 5 of 100 skulls. They emphasized that these bony bridges may be one of the reasons of the mandibular neuralgia. ${ }^{5}$ Out of 361 dry skull bones, Pinar et at found completely ossified pterygospinous ligament in 12 cases and incompletely ossified ligaments in 35 cases. ${ }^{4}$ Lüdinghausen at al. reported the complete pterygospinous bony bar as $1.85 \%$ on cadaver and as $6 \%$ on dry human skulls. ${ }^{9}$ Out of 416 dry human skulls, Nayak at al observed $3.84 \%$ with incomplete pterygospinous ligament and $5.76 \%$ with complete pterygospinous bony bar. ${ }^{10}$ Peker et al studied 452 adult dry crania and found completely ossified pterygospinous ligament in $5.5 \%$ of the cases. ${ }^{11}$ Antonopoulou et al observed incompletely ossified pterygospinous ligaments in $2.5 \%$ skulls and completely ossified pterygospinous bridge bilaterally in 
$2 \%$ of the skulls by 3D reconstruction in a CT image. ${ }^{12}$ Presence of ossified pterygospinous ligament may produce failure of anaesthesia during treatment of trigeminal neuralgia ${ }^{13}$, and difficulty in thermocoagulation of trigeminal ganglion. ${ }^{14}$ According to Newton and Potts an ossified pterygospinous ligament can be an obstacle in a radiograpically guided trigeminal ganglion blockage. ${ }^{15} \mathrm{~A}$ study done on 312 dry human skulls from the collection of Universidade

Federal de Sao Paulo (UNIFESP) were used to assess the presence of total or partial ossification in pterygospinous (Types I and II). ${ }^{16}$

Hence it is concluded that ossified pterygspinous ligament is highly rare structure and its presence can be a problem for anaesthetics, neurologists and oral maxillofacial surgeons.

\section{Refrances-}

[1] Standring S. Grays Anatomy. The Anatomical basis of clinical practice. Edinburgh; Elsevier Churchill Livingstone. 2005:521.

[2] Soubhagya R Nayak, Rajalakshmi Rai. An unusual course and entrapment of the lingual nerve in the infratemporal fossa. Comp. Anat.2008;109[11]525-527.

[3] Peuker ET, Fischer G, Filler TJ. Entrapment of the lingual nerve due to an ossified pterygospinous ligament. Clin. Anat. 2001; 14: $282-284$.

[4] ] Pinar Y, Arsu G, Aktan Ikiz ZA, Bilge O. Pterygospinous and pterygoalar bridges. Sendrom. 2004 ; 16 66-69.

[5] Krmpotic-Nemanic J, Vinter I, Hat J, Jalsovec D. Mandibular neuralgia due to anatomical variations. Eur. Arch. Otorhinolaryngol. 1999; 256: 205-208

[6] Vijaykumar Shankar Shinde, Mallikarjun M. Journal of Clinical and Diagnostic Research. 2011 October, Vol-5(5): 978-979

[7] Int. J. Morphol.,28(2):405-408, 2010.Anatomical Study of the Pterygospinous and PterygoalarBony Bridges and Foramens in Dried Crania and itsClinical Relevance

[8] Kapur E, Dilberovic F, Redzepagic S, Berhamovic E. Variation in the lateral plate of the pterygoid process and the lateral subzygomatic approach to the mandibular nerve. Med Arch 2000;54:133-137.

[9] von Ludinghausen M, Kageyama I, Miura M, Alkhatib M. Morphological peculiarities of the deep infratemporal fossa in advanced age. Surg. Radiol. Anat. 2006; 28: 284-292.

[10] Nayak SR, Saralaya V, Prabhu LV, Pai MM, Vadgaonkar R, Dcosta S.The pterygospinous bar and the foramina in Indian skulls: Incidence and phylogenetic significance. Surg Rad Anat. 2007;29:5-7.

[11] Peker T, Karakose M, Anil A, Turgut HB, Gulekon N. The incidence of basal sphenoid bony bridges in dried crania and cadavers: Their anthropological and clinical relevance. Euro J Morphol. 2002; 40: 171-180.

[12] Antonopoulou M, Piagou M, Anagnostopoulou S. An anatomical study of the pterygospinous and pterygoalar bars and foraminatheir clinical relevance. J Craniomaxillofac Surg.2008; 36:104-108.

[13] Sweet WH. The treatment of trigeminal neuralgia. New Engl J Med 1986; 315: 174-177.

[14] Loughner BA, Larkin LH, Mahan PE. Nerve entrapment in the lateral pterygoid muscle. Oral Surg Oral Med Oral Pathol 1990; 69: 299-306.

[15] Kapur E, Dilberovic F, Redzepagic S, Berhamovic E. Variation in the lateral plate of the pterygoid process and the lateral subzygomatic approach to the mandibular nerve. Med. Arh. 2000; 54: 133-137.

[16] Anatomical Study of the Pterygospinous and Pterygoalar Bony Bridges and Foramens in Dried Crania and its Clinical Relevance. ] Int. J. Morphol.,28(2):405-408, 2010

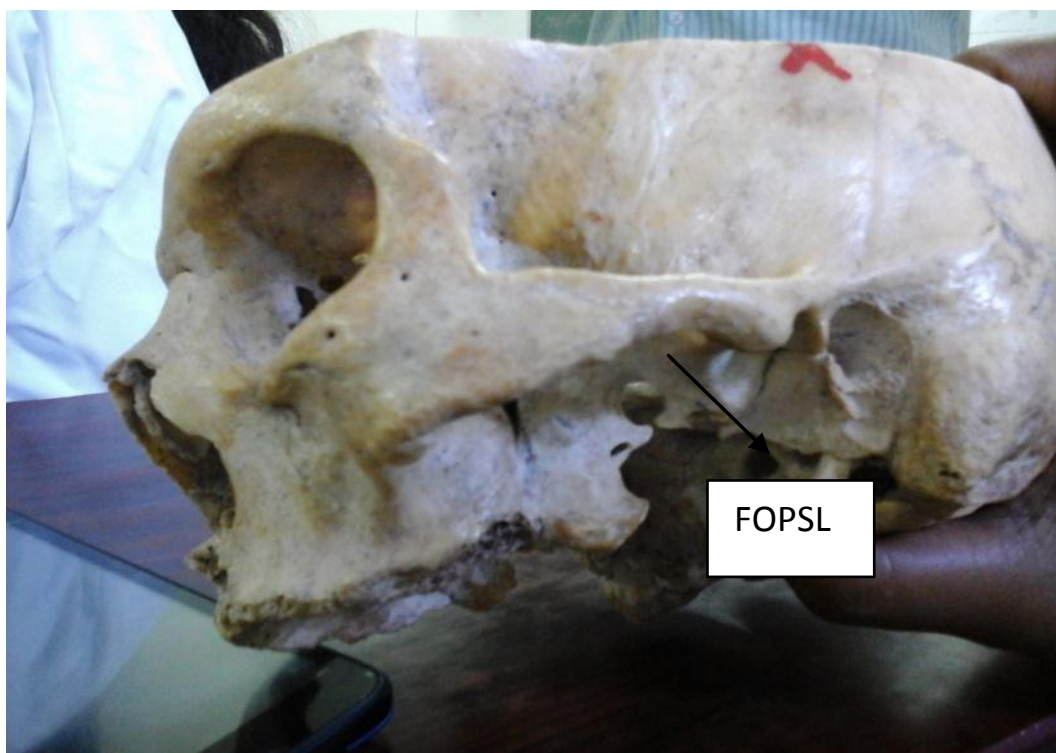

FIG 1- Showing almost fully ossified pterygospinous ligament[FOPSL] on left side. 


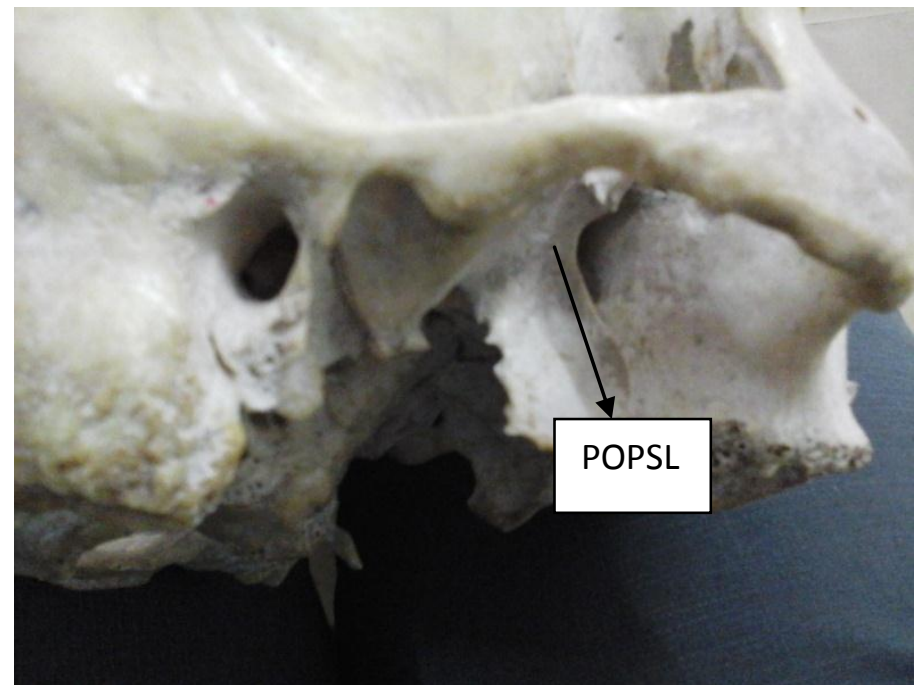

FIG.-2- Showing partial ossified pterygospinous ligament[POPSL] on right side.

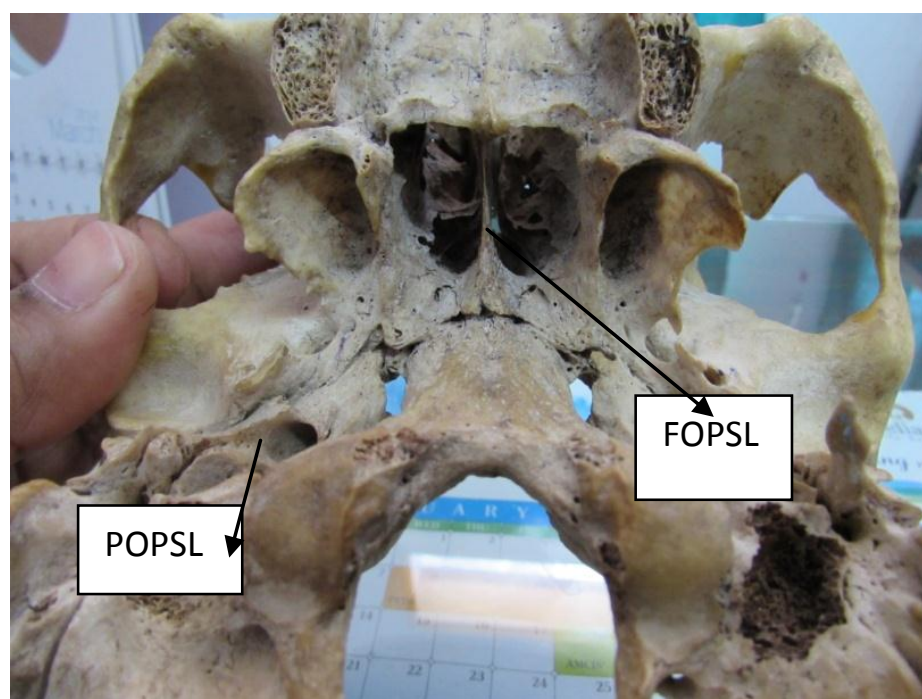

FIG.3- Showing the skull with almost fully ossified pterygospinous ligament[FOPSL] on left side and partial ossified pterygospinous ligament[POPSL] on right side. 